\title{
Transplante de fração total de células mononucleares ou fração vascular estromal associada à membrana celulósica em feridas cutâneas experimentais de coelhos
}

\author{
Total fraction of mononuclear cell or stromal vascular fraction transplant associated with \\ cellulosic membrane in experimental cutaneous wounds in rabbits
}

\author{
Tiago Luis Eilers TREICHEL ${ }^{1}$; Marina Gabriela Monteiro Carvalho Mori da CUNHA ${ }^{1}$; João Paulo \\ Monteiro Carvalho Mori da CUNHA ${ }^{1}$; Eduardo de Bastos SANTOS JÚNIOR ${ }^{1}$; Paulo de Tarso de \\ Oliveira LEME JÚNIOR ${ }^{1}$; Márcio Machado COSTA ${ }^{1}$; Ney Luis PIPPI ${ }^{2}$; Sônia Teresinha dos Anjos \\ LOPES $^{2}$; Rafael Almeida FIGHERA ${ }^{3}$; Maurício Borges da ROSA ${ }^{4}$

\footnotetext{
${ }^{2}$ Departamento de Clínica de Pequenos Animais da Universidade Federal de Santa Maria, Santa Maria - RS, Brasil

${ }^{3}$ Departamento de Patologia da Universidade Federal de Santa Maria, Santa Maria - RS, Brasil

${ }^{4}$ Discente do Curso de Medicina Veterinária da Universidade Federal de Santa Maria, Santa Maria - RS, Brasil
} \\ ${ }^{1}$ Programa de Pós-graduação em Medicina Veterinária da Universidade Federal de Santa Maria, Santa Maria - RS, Brasil
}

\begin{abstract}
Resumo
A pele apresenta diversas funções importantes para o organismo. A manutenção de sua integridade é fundamental, entre outras, para impedir a penetração de microrganismos e a perda de líquidos essenciais à manutenção da vida. Por estar constantemente exposta ao meio ambiente, a pele é altamente susceptível a traumas que podem acarretar soluções de continuidade. A cicatrização da pele ferida deve ser rápida e diversas alternativas são buscadas, visando à redução do tempo de reparo a fim de garantir cicatriz funcional e esteticamente aceitável. Uma opção cada vez mais viável para reparar tecidos danificados é a terapia celular com células-tronco adultas. Os objetivos deste trabalho consistiram em avaliar o transplante da fração total de células mononucleares (FTCM) da medula óssea (MO) e da fração vascular estromal (FVE) do tecido adiposo (TA), associado ao uso da membrana celulósica. Para realização deste experimento, 20 coelhos foram divididos aleatoriamente em quatro grupos com cinco animais cada. Após a indução da ferida cutânea experimental, o grupo A, não recebeu nenhum tratamento, o grupo $\mathrm{B}$, recebeu apenas membrana celulósica e os grupos $\mathrm{C}$ e $\mathrm{D}$, além de receberem a membrana, foram submetidos a transplante autólogo da FTCM, com valor total de células entre 6,92 x $10^{6}$ a 4,91 x $10^{7}$ e uma viabilidade de 82 a $97 \%$ ou da FVE, com valor total de células entre 9,6 x $10^{5}$ e 6,5 x $10^{6}$ e uma viabilidade de 66 a 87\%, respectivamente. Ao final do período de avaliação, os três grupos tratados apresentaram diferença estatística significativa da área da ferida em relação ao grupo controle e o grupo que recebeu a FVE do tecido adiposo apresentou o menor tempo de cicatrização da ferida.
\end{abstract}

Palavras-chave: Fração de células. Reparo. Ferida. Pele. Coelho.

\begin{abstract}
The skin presents various important functions to the organism. The maintenance of its integrity is fundamental, among others, to prevent penetration of microorganisms and exit of liquids essential to life maintenance. Due to its constant environment exposure, the skin is highly susceptible to trauma which can result solutions of continuity. The healing of wounded skin should be fast and many alternatives are searched for, aiming to reduce repair time and to guarantee a functional and esthetically acceptable scar. One option to repair injured tissues which is ever more viable is cellular therapy with adult stem cells. The aims of this study consisted in evaluating the transplant of total mononuclear cell fraction (TMCF) from bone marrow (BM) or stromal vascular fraction (SVF) from adipose tissue (AT), associated with the use of cellulose membrane. To carry out this experiment, 20 rabbits were randomly divided in four groups with five animals each. After induction of the experimental cutaneous wound, Group A did not receive any treatment; group $\mathrm{B}$ received only cellulose membrane; and groups $\mathrm{C}$ and $\mathrm{D}$, in addition to receiving the membrane, were submitted to autologous transplant of TMCF, with total cell value between $6,92 \times 10^{6}$ and $4,91 \times 10^{7}$ and a viability of 82 to $97 \%$ or SVF, with total cell value between $9,6 \times 10^{5}$ and $6,5 \times 10^{6}$ and a viability of 66 a $87 \%$, respectively. At the end of the evaluation period, the three treated groups presented significant statistical difference of wound area in relation to the control group, and the group which received SVF from adipose tissue presented the shortest wound healing time.
\end{abstract}

Keywords: Fraction of cells. Repair. Wound. Skin. Rabbit. 


\section{Introdução}

A pele junto com os seus anexos é caracterizada como o maior órgão do corpo $^{1,2,3}$. É formada principalmente pela epiderme, derme e uma terceira camada variável, a hipoderme ${ }^{4,5}$. A epiderme é composta por queratinócitos, melanócitos, células de Langerhans e células de Merkel, a derme por sua vez é composta pela camada papilar e a camada reticular ${ }^{1,2}$.

Quando um trauma causa solução de continuidade na pele, deixando expostos os tecidos subjacentes, tem-se uma ferida ${ }^{6}$, que pode estar presente em qualquer região corporal do animal e as suas causas mais comuns podem envolver traumas térmicos, químicos ou mecânicos acidentais ou cirúrgicos ${ }^{7,8,9}$. A pele, por apresentar estruturas de várias camadas germinativas, não apresenta capacidade regenerativa, com exceção da epiderme ${ }^{10}$. A cicatrização tem como objetivo reparar o tecido ferido substituindo-o por colágeno ${ }^{5}$. Entretanto, algumas complicações como pouca elasticidade da pele, escassez de tecidos locais ou perda cutânea podem inviabilizar a cicatrização $0^{6,7}$.

Características das células-tronco mesenquimais (CTM), como auto-renovação e diferenciação em diversos tipos celulares, têm recebido atenção significante na atualidade ${ }^{11,12,13,14,15,16}$. Em vista disso, a terapia celular com células-tronco mesenquimais para reparar tecidos danificados, passa a ser considerada alternativa viável ${ }^{17}$. Para aplicação clínica, estas células são isoladas do sangue da medula óssea ou do tecido adiposo ${ }^{13}$. No entanto, tem sido sugerido que as células-tronco, quando injetadas sozinhas, não reparam os tecidos de maneira satisfatória, mas a combinação destas células com alguns componentes, conhecidos como matriz ou scaffold, podem resultar em processo bem sucedido ${ }^{13}$.

Neste trabalho avaliou-se a viabilidade clínica e a eficácia da terapia celular, por meio de transplante autógeno da fração total de células mononucleares (FTCM) da medula óssea (MO) ou da fração vascular estromal (FVE) do tecido adiposo (TA), para o tratamento de feridas cutâneas induzidas experimentalmente em coelhos. Desta maneira, os objetivos foram: 1) comparar a influência e a eficácia da membrana utilizada como scaffold, com a lesão sem o biomaterial, 2) comparar a reparação cutânea com e sem o transplante das frações celulares, avaliando o tempo de cicatrização e a qualidade cicatricial das feridas.

\section{Material e Método}

Este estudo foi submetido à aprovação do Comitê de Ética e Experimentação Animal da Universidade Federal de Santa Maria, seguindo os princípios éticos do Conselho Nacional de Controle de Experimentação Animal (CONCEA), julgado e aprovado no processo número: 23081.011545/2009-31. Para a realização deste experimento, foram utilizados 20 coelhos (Oryctolagus cuniculus) da raça Nova Zelândia Branco, hígidos, de ambos os sexos, com idade aproximada de seis meses e massa corporal média de $4,5 \mathrm{~kg}$. Todos os animais foram alojados em gaiolas individuais, por período mínimo de 15 dias para sua adaptação e posteriormente distribuídos aleatoriamente em quatro grupos experimentais (A, B, C e D) com cinco animais cada, correspondendo a cada tipo de tratamento. Durante todo o período do experimento os animais receberam ração e água ad libitum.

A medicação pré-anestésica foi constituída da associação de cloridrato de cetamina (Cetamina ${ }^{\circ}$ - Univet S.A. São Paulo, São Paulo), na dose de $20 \mathrm{mg} \mathrm{kg}^{-1}$, maleato de midazolam (Dormonid Injetável ${ }^{\circledR}$ - Roche Brasil. Jacarepaguá, Rio de Janeiro), $2 \mathrm{mg} \mathrm{kg}^{-1}$ e sulfato de morfina (Dimorf Injetável ${ }^{\circledR}$ - Cristália Produtos Farmacêuticos Ltda. Itapira, São Paulo), $5 \mathrm{mg} \mathrm{kg}^{-1}$, todos por via intramuscular (IM). Após, administrou-se sulfato de atropina (Hytropin Injetável ${ }^{\circledR}$ - Hipolabor Farmacêutica Ltda. Sabará, Minas Gerais), na dose de $0,05 \mathrm{mg} \mathrm{kg}^{-1}$ e posterior indução anestésica com propofol (Diprivan ${ }^{\circledast}$ - AstraZeneca. Cotia, São Paulo), 10 
$\mathrm{mg} \mathrm{kg}{ }^{-1}$, ambos pela via intravenosa (IV). A manutenção anestésica foi realizada com isofluorano (Isoflurane ${ }^{\oplus}$ - Cristália Produtos Farmacêuticos Ltda. Itapira, São Paulo) através do uso de máscara, com sistema inalatório sem reinalação, vaporizado em 100\% de oxigênio, com respiração espontânea.

Fração total de células mononucleares (FTCM) da medula óssea (MO)

$\mathrm{O}$ sangue da $\mathrm{MO}$ foi colhido dos fêmures dos animais. A criação de um túnel na fossa trocantérica em direção ao canal medular com pino intramedular, permitiu a introdução de agulha hipodérmica 40 x 16, para aspiração de $5 \mathrm{~mL} \mathrm{~kg}^{-1}$ de sangue da MO com seringa de $10 \mathrm{~mL}$, previamente heparinizada (Liquemine ${ }^{\circledast} 10.000$ UI - Roche Brasil. Jacarepaguá, Rio de Janeiro). A incisão de pele foi ocluída com uma gota de cola de secagem instantânea a base de éster de cianoacrilato (Super Bonder Precisão ${ }^{\circledR}$ - Loctite. Itapevi, São Paulo).

O sangue da $\mathrm{MO}$, assim que colhido, foi depositado em uma bolsa de transfusão sanguínea, contendo 0,01 $\mathrm{mL}$ de heparina e $1 \mathrm{~mL}$ de solução de cloreto de sódio a $0,9 \%$ para cada $10 \mathrm{~mL}$ de volume. No interior da capela de fluxo laminar, o sangue foi filtrado (500 $\mu \mathrm{m})$ e separado em tubos Falcon de $50 \mathrm{~mL}$, contendo solução de Hanks (Hanks' Balanced Salts H1387$1 L^{\circ}$ - Sigma-Aldrich. Sant Louis, Estados Unidos), na proporção de 1:1, e centrifugado a $440 \mathrm{G}$, durante cinco minutos. Após a primeira centrifugação, o sobrenadante foi retirado e o sangue da MO transferido para um novo tubo, contendo gradiente de densidade, Ficoll-hypaque 1.077 (Histopaque $1077^{\circledR}$ - SigmaAldrich. Sant Louis, Estados Unidos), na proporção 1:1 de sangue:gradiente, de acordo com a técnica de Boyum modificada por Olsson ${ }^{18}$.

O tubo contendo a FTCM e o gradiente foi centrifugado a $440 \mathrm{G}$, em temperatura ambiente, durante 25 minutos, proporcionando visualização de halo contendo células mononucleares (Figura 1A). O halo foi aspirado com pipeta automática, depositado em ou- tro tubo e lavado com $10 \mathrm{~mL}$ de Dulbecco's Modified Eagle’s Medium (DMEM) (Gibco $11885^{\circ}$ - Invitrogen. São Paulo, São Paulo) associado a Soro Fetal Bovino (SFB) $($ F9665 - Sigma-Aldrich. Saint Louis, Estados Unidos), para ser centrifugado a $440 \mathrm{G}$ por cinco minutos, procedimento repetido duas vezes. Após a remoção do sobrenadante, foi obtido na base do tubo, como produto final, um botão celular (pellet). Uma alíquota de $70 \mu \mathrm{l}$ foi colhida para quantificação manual de células mononucleares e teste de viabilidade. $\mathrm{O}$ restante do botão foi imediatamente aplicado nos animais do Grupo C, no local da lesão.

Fração vascular estromal (FVE) do tecido adiposo (TA)

O fragmento de tecido adiposo, pesando dez gramas, foi obtido por meio de incisão na linha mediana dorsal na região interescapular. $\mathrm{O}$ espaço morto foi reduzido com fio absorvível sintético 3-0 (Vicryl ${ }^{\circledR}$ - Ethicon-Johnson. São José dos Campos, São Paulo), em padrão contínuo simples e a dermorrafia realizada com fio inabsorvível sintético 4-0 (Mononylon ${ }^{\circledast}$ - Ethicon-Johnson. São José dos Campos, São Paulo), com pontos isolados de Wolff. Os pontos de pele foram removidos sete dias após o procedimento cirúrgico.

O fragmento de TA colhido foi imediatamente depositado em um recipiente de vidro, estéril, contendo $150 \mathrm{~mL}$ de solução de Hanks. No interior da capela de fluxo laminar o tecido foi transferido para uma placa de Petri e, com o auxílio de tesoura, seccionado várias vezes. Os pequenos fragmentos foram lavados três vezes, com solução de Hanks e transferidos para tubos Falcon de $50 \mathrm{~mL}$ acrescidos de solução de $1 \mathrm{mg} / \mathrm{mL}$ de colagenase do tipo I (C0130 - Sigma-Aldrich. Saint Louis, Estados Unidos) e tipo II (C6885 - SigmaAldrich. Saint Louis, Estados Unidos), 0,5 mg/mL de cada, na proporção 1:3 (volume:volume).

Os tubos permaneceram em banho-maria, durante 25 minutos, em temperatura de $37^{\circ} \mathrm{C}$ e agitados manualmente, a cada cinco minutos. Após o banhomaria (Figura 1B), a colagenase foi neutralizada atra- 


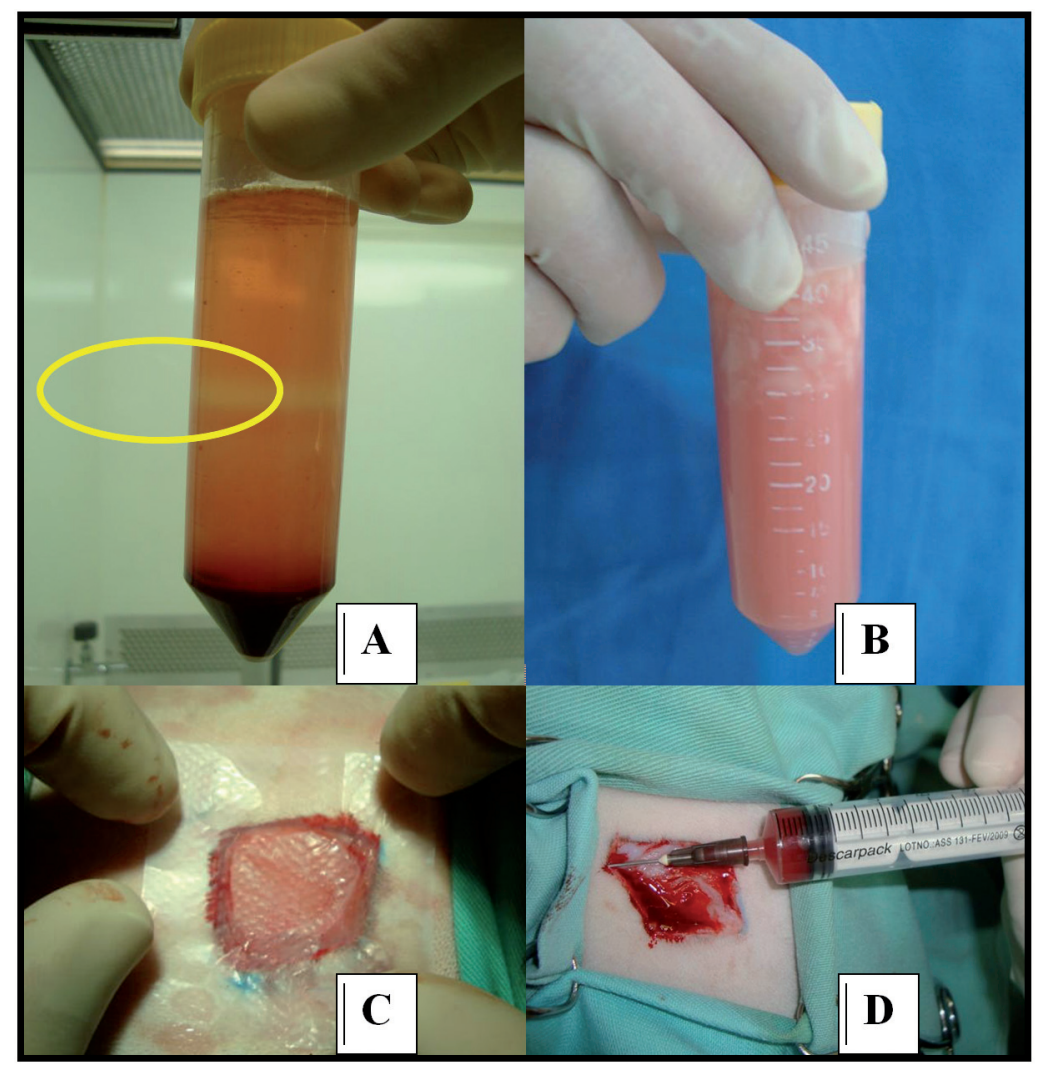

Figura 1 - A) Tubo Falcon contendo halo da fração de células mononucleares (destacado) da medula óssea de coelho. Esse halo é formado após centrifugação com gradiente de densidade. No fundo cônico observa-se a deposição de hemácias e granulócitos. B) Tubo Falcon contendo tecido adiposo após a digestão pela colagenase. Observar aspecto leitoso indicando completa digestão. C) Aplicação da membrana celulósica sobre a ferida cirúrgica, imediatamente após a criação do defeito, nos coelhos dos grupos B, C e D. D) Aplicação da fração vascular estromal no espaço subcutâneo, na borda caudal da ferida cirúrgica, nos coelhos do grupo D

vés da adição de meio completo com $10 \%$ de SFB, em proporção 1:1. Os tubos de TA com o meio completo adicionado foram centrifugados a $600 \mathrm{G}$, em temperatura ambiente, durante cinco minutos. Realizou-se agitação manual vigorosa dos tubos e os mesmos foram recolocados na centrifuga, por mais cinco minutos, com mesma rotação.

O sobrenadante foi descartado e a fração lavada com meio completo e centrifugada, desta vez, a 440 $\mathrm{G}$, em temperatura ambiente, durante cinco minutos. O procedimento de lavagem foi repetido novamente e ao término da nova centrifugação o sobrenadante descartado e a FVE ressuspendida em $1 \mathrm{~mL}$ de meio completo. Alíquota de $70 \mu \mathrm{l}$ foi colhida para quantificação manual de células mononucleares e teste de viabilidade. O restante do botão foi imediatamente aplicado nos animais do Grupo D, no local da lesão.

\section{Criação do defeito cutâneo e tratamentos}

Incisou-se a pele da parede torácica direita, sobre a região da última costela, criando ferida medindo aproximadamente $2 \times 2 \mathrm{~cm}$. Vasos sangrantes identificados foram pinçados e a hemostasia realizada somente por compressão ou por forcitorção. No local em que ocorreu a criação do defeito cirúrgico experimental, houve o tratamento da lesão de acordo com o grupo que o animal pertencia. 
O Grupo A, controle negativo, não recebeu nenhum tratamento para fechamento do defeito criado, apenas curativo com gaze e atadura, trocados diariamente, além de gel lubrificante à base de água $\left(\mathrm{K}-\mathrm{Y} \mathrm{Gel}{ }^{\circledR}\right.$ Johnson \& Johnson do Brasil. São José dos Campos, São Paulo). Nos animais do Grupo B, a membrana celulósica medindo $5 \mathrm{~cm}^{2}$ (Bioprat ${ }^{\oplus}$ - Bionext Produtos Biotecnológicos Ltda. São Paulo, São Paulo), utilizada como scaffold, foi posicionada sobre a lesão. As bordas da membrana foram fixadas na pele dos animais com cola de secagem instantânea (Figura 1C).

Os animais do Grupo C e Grupo D receberam, além da membrana utilizada no grupo B, o botão celular (pellet) contendo a FTCM isolada da MO ou a FVE do TA, respectivamente, imediatamente após a colheita e processamento. $\mathrm{O}$ pellet foi aspirado com uma seringa hipodérmica de $3 \mathrm{~mL}$ e agulha $40 \times 12$ e aplicado no espaço subcutâneo, nas quatro bordas do defeito criado, próximo ao leito da ferida cirúrgica (Figura 1D).

No pós-operatório administrou-se meloxican (Maxican $2 \%$ - Ouro Fino. Ribeirão Preto, São Paulo), na dose de $0,2 \mathrm{mg} \mathrm{kg}^{-1}$, via subcutânea, uma vez ao dia, durante três dias e $5 \mathrm{mg} \mathrm{kg}^{-1}$ de sulfato de morfina (Dimorf Injetável ${ }^{\oplus}$ - Cristália Produtos Farmacêuticos Ltda. Itapira, São Paulo), via intramuscular IM, quatro vezes ao dia, durante três dias. Os animais do grupo A foram submetidos à limpeza da ferida cirúrgica com solução fisiológica uma vez ao dia. A troca do curativo foi realizada diariamente nos animais de todos os grupos. Ao término do experimento e período de avaliação pós-cirúrgica, todos os animais foram encaminhados para doação.

\section{Resultados}

A metodologia utilizada para o processamento da medula óssea permitiu a obtenção de botões celulares, para aplicação no animal, com valor total de células entre $6,92 \times 10^{6}$ a $4,91 \times 10^{7}$ (média de $2,49 \times 10^{7}$ ) e viabilidade de 82 a 97\% (média de 90,75\%) na amostra de quatro botões, pois um apresentou agregação celular. Com relação ao processamento do tecido adiposo, foi possível obter botões celulares, com valor total de células entre 9,6 $\times 10^{5}$ e 6,5 × $10^{6}$ (média de $2,7 \times 10^{6}$ ) e viabilidade de 66 a $87 \%$ (média de 79,6\%) (Tabela 1).

Tabela 1 - Número de células mononucleares totais $(\mathrm{mL})$ e viabilidade celular (\%) obtidos na amostra e no botão celular aplicado, após o processamento do sangue da medula óssea e do fragmento de tecido adiposo dos coelhos dos grupos $\mathrm{C}$ e D, respectivamente

\begin{tabular}{cccccc}
\hline & & \multicolumn{2}{c}{ Amostra } & \multicolumn{2}{c}{ Botão celular aplicado } \\
\cline { 3 - 6 } Grupo & Animal & $\begin{array}{c}\text { Número de células } \\
\text { mononucleares totais } \\
\text { por mililitro }\end{array}$ & Viabilidade $(\%)$ & $\begin{array}{c}\text { Volume total do pellet } \\
(\mathrm{mL})\end{array}$ & $\begin{array}{c}\text { Total de células } \\
\text { mononucleares }\end{array}$ \\
\hline C & 1 & $2,77 \times 10^{4}$ & $88 \%$ & $0,25 \mathrm{~mL}$ & $6,92 \times 10^{6}$ \\
C & 2 & $2,05 \times 10^{5}$ & $97 \%$ & $0,15 \mathrm{~mL}$ & $3,07 \times 10^{7}$ \\
C & 3 & $1,78 \times 10^{5}$ & Agregada & $0,145 \mathrm{~mL}$ & $2,58 \times 10^{7}$ \\
C & 4 & $5,05 \times 10^{4}$ & $82 \%$ & $0,24 \mathrm{~mL}$ & $1,21 \times 10^{7}$ \\
C & 5 & $9,82 \times 10^{4}$ & $96 \%$ & $0,50 \mathrm{~mL}$ & $4,91 \times 10^{7}$ \\
D & 1 & $4,1 \times 10^{3}$ & $0,5 \mathrm{~mL}$ & $2,05 \times 10^{6}$ \\
D & 2 & $6,5 \times 10^{3}$ & $86 \%$ & $1 \mathrm{~mL}$ & $6,5 \times 10^{6}$ \\
D & 3 & $2,2 \times 10^{3}$ & $87 \%$ & $1 \mathrm{~mL}$ & $2,2 \times 10^{6}$ \\
D & 4 & $1,2 \times 10^{3}$ & $87 \%$ & $0,8 \mathrm{~mL}$ & $9,6 \times 10^{5}$ \\
D & 5 & $8,9 \times 10^{2}$ & $76 \%$ & $2 \mathrm{~mL}$ & $1,78 \times 10^{6}$ \\
\hline
\end{tabular}


Para avaliação da planimetria, os animais foram submetidos à mensuração de suas feridas (altura e largura) no momento da criação da ferida (dia 0) e aos sete, 14 e 21 dias de pós-operatório, sendo que, para o cálculo da área da ferida, foi utilizada a fórmula da área do quadrado. A biópsia tecidual foi realizada aos dias sete, 14 e 21 após a criação do defeito, com o auxílio de um punch de $6 \mathrm{~mm}$, na interface entre o tecido saudável e a ferida.
Para correção das médias de planimetria obtidas de cada grupo, foi utilizado Teste de Tukey, através de software computacional estatístico SAS ${ }^{\bullet}$ (Tabela 2), comparando os quatro grupos entre si. As médias corrigidas, no momento da criação do defeito cirúrgico não apresentaram diferença estatística significativa entre os grupos. Aos sete dias de pós-operatório, os animais dos grupos que receberam a membrana celulósica (grupo B), FTCM (grupo C) e FVE (grupo D),

Tabela 2 - Médias obtidas dos grupos experimentais para altura, largura $(\mathrm{cm})$ e área $\left(\mathrm{cm}^{2}\right)$, nos quatro tempos de avaliação, corrigidas estatisticamente pelo Teste de Tukey e desvio-padrão

\begin{tabular}{ccccc}
\hline DIA & GRUPO & Altura (cm) & Largura (cm) & Área $\left(\mathbf{c m}^{2}\right)$ \\
\hline 0 & $\mathrm{~A}$ & $2,56^{\mathrm{a}}$ & $2,12^{\mathrm{a}}$ & $5,448^{\mathrm{a}}$ \\
0 & $\mathrm{~B}$ & $2,22^{\mathrm{a}}$ & $2,24^{\mathrm{a}}$ & $4,988^{\mathrm{a}}$ \\
0 & $\mathrm{C}$ & $2,48^{\mathrm{a}}$ & $2,10^{\mathrm{a}}$ & $5,168^{\mathrm{a}}$ \\
0 & $\mathrm{D}$ & $2,28^{\mathrm{a}}$ & $2,16^{\mathrm{a}}$ & $4,896^{\mathrm{a}}$ \\
\hline 0 & Desvio Padrão & $\pm 0,273404$ & $\pm 0,272947$ & $\pm 0,823110$ \\
\hline 7 & $\mathrm{~A}$ & $2,26^{\mathrm{a}}$ & $2,14^{\mathrm{a}}$ & $4,830^{\mathrm{a}}$ \\
7 & $\mathrm{~B}$ & $1,80^{\mathrm{ab}}$ & $1,68^{\mathrm{ab}}$ & $3,130^{\mathrm{ab}}$ \\
7 & $\mathrm{C}$ & $2,06^{\mathrm{ab}}$ & $1,82^{\mathrm{ab}}$ & $3,744^{\mathrm{ab}}$ \\
7 & $\mathrm{D}$ & $1,46^{\mathrm{b}}$ & $1,36^{\mathrm{b}}$ & $2,114^{\mathrm{b}}$ \\
\hline 7 & Desvio Padrão & $\pm 0,383732$ & $\pm 0,367423$ & $\pm 1,096461$ \\
\hline 14 & $\mathrm{~A}$ & $1,60^{\mathrm{a}}$ & $1,38^{\mathrm{a}}$ & $2,346^{\mathrm{a}}$ \\
14 & $\mathrm{~B}$ & $1,02^{\mathrm{b}}$ & $0,94^{\mathrm{b}}$ & $1,010^{\mathrm{b}}$ \\
14 & $\mathrm{C}$ & $0,94^{\mathrm{b}}$ & $0,76^{\mathrm{b}}$ & $0,710^{\mathrm{b}}$ \\
14 & $\mathrm{D}$ & $0,68^{\mathrm{b}}$ & $0,72^{\mathrm{b}}$ & $0,536^{\mathrm{b}}$ \\
\hline 14 & Desvio Padrão & $\pm 0,307002$ & $\pm 0,297909$ & $\pm 0,652238$ \\
\hline 21 & $\mathrm{~A}$ & $0,96^{\mathrm{a}}$ & $0,90^{\mathrm{a}}$ & $0,918^{\mathrm{a}}$ \\
21 & $\mathrm{~B}$ & $0,50^{\mathrm{b}}$ & $0,50^{\mathrm{b}}$ & $0,254^{\mathrm{b}}$ \\
21 & $\mathrm{C}$ & $0,0^{\mathrm{c}}$ & $0,0^{\mathrm{c}}$ & $0,0^{\mathrm{b}}$ \\
21 & $\mathrm{D}$ & $0,0^{\mathrm{c}}$ & $0,0^{\mathrm{c}}$ & $0,0^{\mathrm{b}}$ \\
\hline 21 & Desvio Padrão & $\pm 0,144049$ & $\pm 0,150000$ & $\pm 0,222064$ \\
\hline
\end{tabular}

* Letras diferentes correspondem à diferença estatística significativa

não diferiram estatisticamente entre si, no entanto, foi possível perceber diferença estatística significante ( $p$ $<0,0001)$ entre o grupo D, que recebeu a FVE do TA, e grupo controle (A).

No $14^{\circ}$ dia de avaliação, os três grupos que receberam algum tipo de tratamento $(B, C$ e $D)$, também não diferiram entre si, porém todos diferiram significantemente $(\mathrm{p}<0,0001)$ do grupo controle (A).
No final do período de avaliação, aos 21 dias de pósoperatório (Figura 2), os grupos tratados (B, C e D) mantiveram-se sem diferença estatística significante entre $s i$, mas diferiram significantemente $(p<0,0001)$ do grupo controle (A).

Após a correção das médias de cada grupo, foi realizada a análise estatística de regressão (Tabela 3). Este teste demonstrou que o grupo controle (A) apresen- 


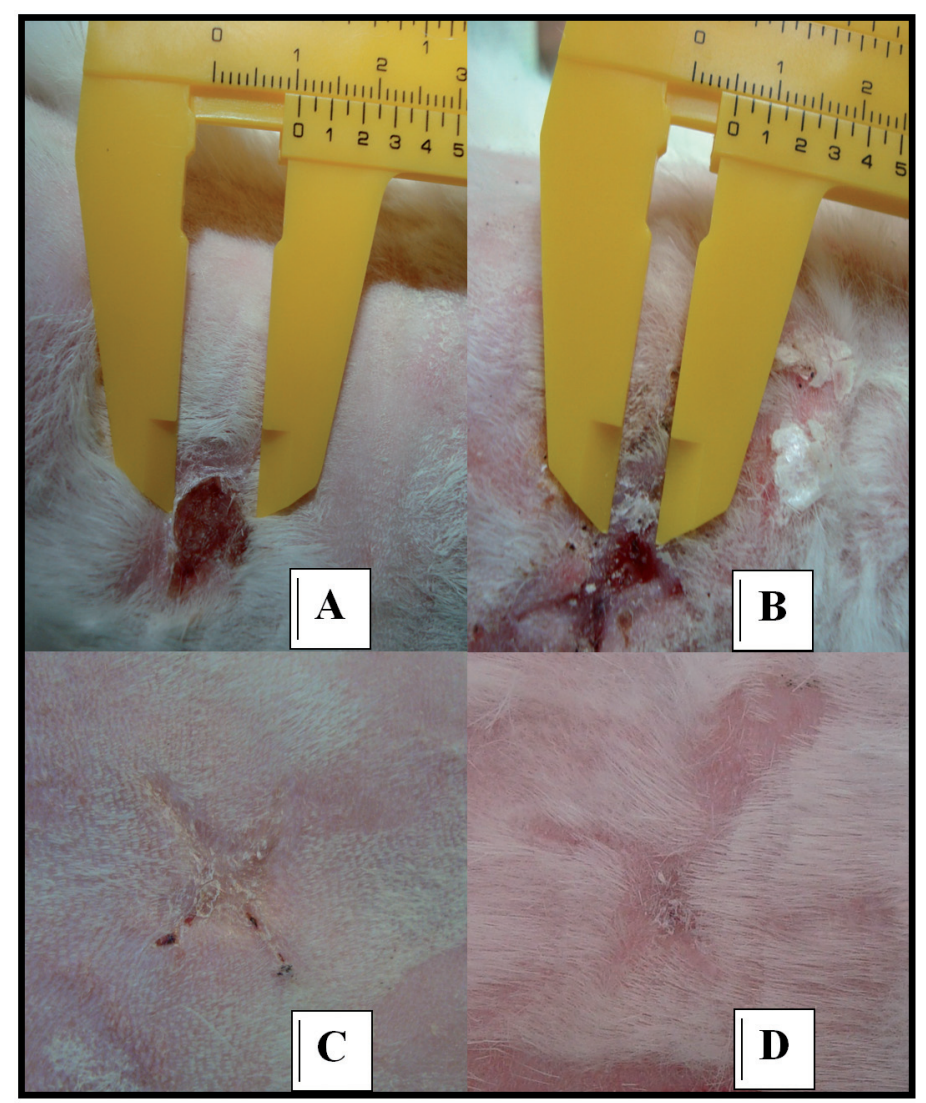

Figura 2 - Aspecto da ferida cutânea dos coelhos, nos quatro grupos experimentais, aos 21 dias de pós-operatório. A letra em destaque corresponde o grupo ao qual pertence o animal

Tabela 3 - Análise de regressão da área dos grupos nos quatro tempos de avaliação

\begin{tabular}{ccccccc}
\hline & \multicolumn{9}{c}{ Períodos de Avaliação (Dias) } & & \\
\cline { 2 - 5 } Grupo & 0 & 7 & 14 & 21 & Rsquare & Nível de Significância \\
\hline A & 5,7966 & 4,189 & 2,581 & 0,974 & $79,64 \%$ & $<.0001$ \\
B & 4,794 & 3,162 & 1,529 & $-0,103$ & $82,07 \%$ & $<.0001$ \\
C & 5,186 & 3,332 & 1,478 & $-0,375$ & $90,33 \%$ & $<.0001$ \\
D & 4,326 & 2,7 & 1,073 & $-0,553$ & $83,20 \%$ & $<.0001$ \\
\hline
\end{tabular}

tou cicatrização completa das feridas, em média, somente aos 25 dias de pós-operatório. O grupo tratado somente com a membrana celulósica (B) apresentou redução completa das feridas no $20^{\circ}$ dia de pós-operatório, em média. Por sua vez, os grupos tratados com FTCM (C) e FVE (D), apresentaram cicatrização completa de suas feridas, em média, nos dias 19 e 18 de pós-operatório, respectivamente (Figura 3).
As biópsias para avaliação histopatológica foram realizadas nos dias sete, 14 e 21 de pós-operatório. As amostras de biópsia foram avaliadas quanto à presença de tecido fibrovascular imaturo dérmico, tecido fibrovascular maduro dérmico, dermatite perivascular profunda heterofílica, dermatite perivascular superficial linfoplasmocitária e dermatite intersticial granulomatosa. Não houve diferença estatística significativa para 


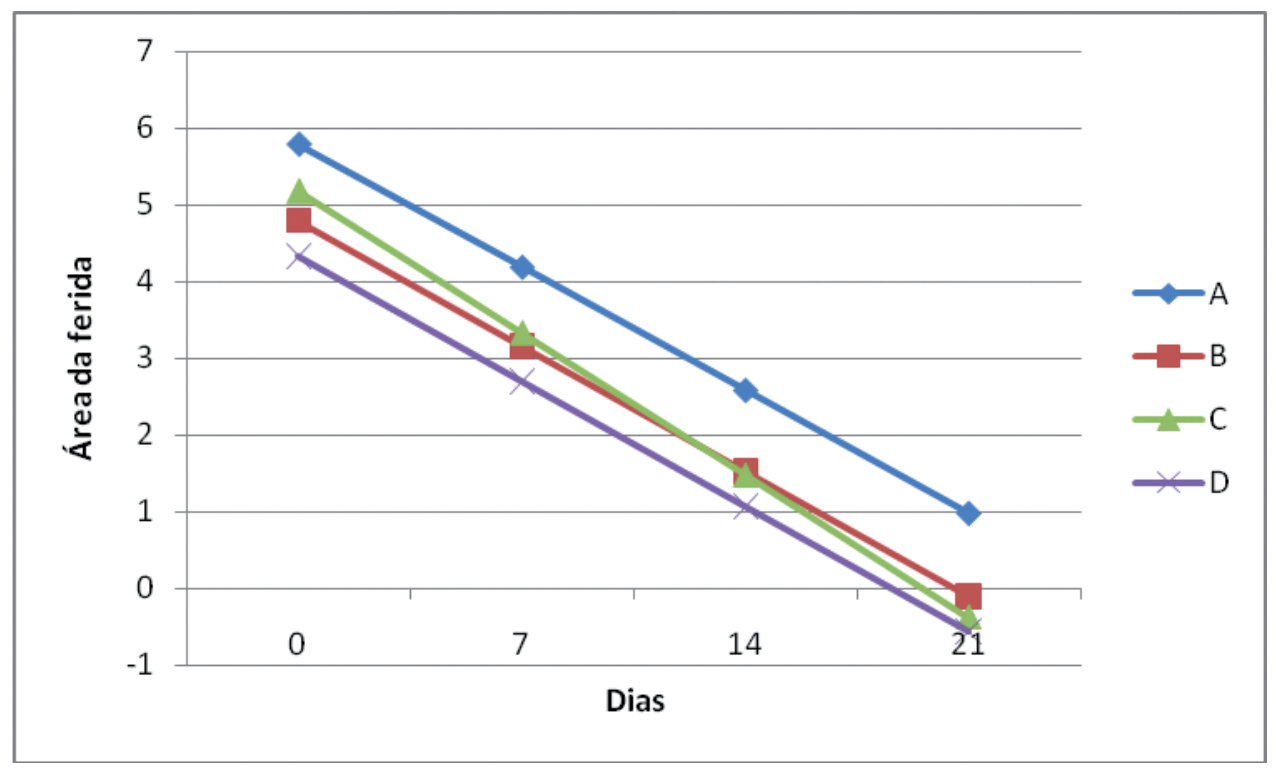

Figura 3 - Gráfico representativo, demonstrando a redução da área das feridas cutâneas dos coelhos, nos quatro grupos experimentais, em relação aos dias de pósoperatório. A letra em destaque corresponde o grupo ao qual pertence o animal

as variáveis avaliadas pela histopatologia, com exceção da dermatite intersticial granulomatosa e da calcificação, que não foram observadas em nenhum dos animais que receberam FCTM ou FVE (Quadro 1).

\section{Discussão}

A membrana celulósica utilizada como scaffold, mostrou-se eficiente quando aplicada isoladamente. Ela provavelmente atuou como barreira mecânica contra a invasão de microrganismos e controlando a perda de fluídos, que devem ser as maiores preocupações no tratamento de ferimentos na pele ${ }^{19}$. Não houve necessidade de remoção da membrana ao término da cicatrização, pois a mesma foi biodegradada, liberando pequenos fragmentos à medida que ocorria o avanço da epitelização, pois as células epiteliais secretam enzimas que dissolvem a base de estruturas de obstáculos que possam ser encontrados no leito da ferida $a^{10}$. Um problema encontrado foi a dificuldade para fixar a membrana sobre a ferida, o que vai contra o preconizado por Burke et al. ${ }^{20}$, que afirmaram que o substituto cutâneo ideal deve ser de fácil aplicação e deve aderir ao leito receptor. Por este motivo optou-se pela utilização da cola de secagem rápida para evitar a queda do curativo biológico.

A colheita do tecido adiposo mostrou-se mais fácil de ser executada, necessitando de menos tempo para ser realizada e proporcionando recuperação pós-operatória mais rápida para o animal. Sugere-se que este método de colheita cause menos dor para o animal, conforme observaram Housman et al. ${ }^{21}$. A colheita de $5 \mathrm{~mL} \mathrm{~kg}^{-1}$ de sangue da $\mathrm{MO}^{22}$ e dez gramas de tecido adiposo, valor determinado por estudos prévios, foram suficientes e permitiram a obtenção de botões celulares, para aplicação no animal, com valores considerados satisfatórios, superando inclusive o preconizado como ideal por Gengozian ${ }^{23}$ para a implantação ("pega") do enxerto $\left(2 \times 10^{6}\right)$. Na avaliação histopatológica pode-se perceber que os coelhos tratados com FTCM ou FVE não apresentaram dermatite intersticial granulomatosa (DIG), o que é benéfico para a cicatrização da ferida cirúrgica. Os animais tratados também não apresentaram calcificação.

O processo de cicatrização da pele ocorre em três fases: inflamatória, proliferativa e de remodelagem ${ }^{24}$. 


\begin{tabular}{|c|c|c|c|c|c|c|c|c|c|c|}
\hline & Úlcera & Crosta & TFID & TFMD & $\begin{array}{l}\text { Fibrose } \\
\text { dérmica }\end{array}$ & $\mathrm{DPPH}$ & DPSLP & DIG & Calcif. & Acantose \\
\hline $\begin{array}{l}\text { A1 } 07 \mathrm{~d} \\
\text { A1 } 14 \mathrm{~d} \\
\text { A1 } 21 \mathrm{~d}\end{array}$ & $\begin{array}{c}+++ \\
- \\
- \\
\end{array}$ & $\begin{array}{c}+++ \\
- \\
- \\
\end{array}$ & $\begin{array}{c}+++ \\
- \\
- \\
\end{array}$ & $\begin{array}{c}- \\
++ \\
-\end{array}$ & $\begin{array}{c}- \\
- \\
+++\end{array}$ & $\begin{array}{l}+ \\
- \\
-\end{array}$ & $\begin{array}{l}- \\
+ \\
-\end{array}$ & $\begin{array}{c}+++ \\
+ \\
+++\end{array}$ & $\begin{array}{c}+ \\
+ \\
+++\end{array}$ & $\begin{array}{c}- \\
+++ \\
+++\end{array}$ \\
\hline $\begin{array}{l}\text { A2 } 07 \mathrm{~d} \\
\text { A2 } 14 \mathrm{~d} \\
\text { A2 } 21 \mathrm{~d}\end{array}$ & $\begin{array}{c}+++ \\
- \\
- \\
\end{array}$ & $\begin{array}{c}++ \\
- \\
- \\
\end{array}$ & $\begin{array}{c}+ \\
+++ \\
- \\
\end{array}$ & $\begin{array}{c}- \\
- \\
+++\end{array}$ & $\begin{array}{l}- \\
- \\
- \\
\end{array}$ & $\begin{array}{l}- \\
+ \\
-\end{array}$ & $\begin{array}{l}- \\
- \\
-\end{array}$ & $\begin{array}{l}- \\
+ \\
+ \\
\end{array}$ & $\begin{array}{l}- \\
+ \\
+\end{array}$ & $\begin{array}{c}- \\
+++ \\
+++\end{array}$ \\
\hline $\begin{array}{l}\text { A3 } 07 \mathrm{~d} \\
\text { A3 } 14 \mathrm{~d} \\
\text { A3 } 21 \mathrm{~d}\end{array}$ & $\begin{array}{c}+++ \\
- \\
-\end{array}$ & $\begin{array}{c}++ \\
- \\
-\end{array}$ & $\begin{array}{c}+++ \\
+++ \\
-\end{array}$ & $\begin{array}{c}- \\
- \\
+++\end{array}$ & $\begin{array}{l}- \\
- \\
-\end{array}$ & $\begin{array}{l}+ \\
+ \\
+\end{array}$ & $\begin{array}{l}- \\
- \\
-\end{array}$ & $\begin{array}{l}- \\
+ \\
-\end{array}$ & $\begin{array}{l}- \\
+ \\
-\end{array}$ & $\begin{array}{c} \\
+ \\
+++ \\
+++\end{array}$ \\
\hline $\begin{array}{l}\text { A4 } 07 \mathrm{~d} \\
\text { A4 } 14 \mathrm{~d} \\
\mathrm{~A} 421 \mathrm{~d}\end{array}$ & $\begin{array}{c}\text { NR } \\
- \\
+++ \\
\end{array}$ & $\begin{array}{c}\text { NR } \\
- \\
+++ \\
\end{array}$ & $\begin{array}{c}\text { NR } \\
++ \\
+++\end{array}$ & $\begin{array}{c}\text { NR } \\
- \\
- \\
\end{array}$ & $\begin{array}{c}\text { NR } \\
- \\
- \\
\end{array}$ & $\begin{array}{c}\mathrm{NR} \\
+ \\
+++\end{array}$ & $\begin{array}{c}\mathrm{NR} \\
- \\
+++\end{array}$ & $\begin{array}{c}\text { NR } \\
+ \\
+ \\
\end{array}$ & $\begin{array}{c}\text { NR } \\
- \\
- \\
\end{array}$ & $\begin{array}{c}\text { NR } \\
+++ \\
- \\
\end{array}$ \\
\hline $\begin{array}{l}\text { A5 } 07 \mathrm{~d} \\
\text { A5 } 14 \mathrm{~d} \\
\text { A5 } 21 \mathrm{~d}\end{array}$ & $\begin{array}{l}- \\
- \\
-\end{array}$ & $\begin{array}{l} \\
- \\
-\end{array}$ & $\begin{array}{l}- \\
+ \\
+\end{array}$ & $\begin{array}{c}- \\
++ \\
+++\end{array}$ & $\begin{array}{l}- \\
- \\
+\end{array}$ & $\begin{array}{l}- \\
- \\
+\end{array}$ & $\begin{array}{l}- \\
- \\
-\end{array}$ & $\begin{array}{c} \\
+ \\
++\end{array}$ & $\begin{array}{c}- \\
+ \\
++\end{array}$ & $\begin{array}{c} \\
+ \\
++ \\
+++\end{array}$ \\
\hline $\begin{array}{l}\text { B1 } 07 d \\
\text { B1 } 14 d \\
\text { B1 } 21 d\end{array}$ & $\begin{array}{c}\text { NR } \\
- \\
-\end{array}$ & $\begin{array}{l}\text { NR } \\
+ \\
+\end{array}$ & $\begin{array}{c}\text { NR } \\
+++ \\
+++\end{array}$ & $\begin{array}{c}\text { NR } \\
- \\
-\end{array}$ & $\begin{array}{c}\text { NR } \\
- \\
-\end{array}$ & $\begin{array}{c}\text { NR } \\
- \\
+\end{array}$ & $\begin{array}{c}\text { NR } \\
- \\
+\end{array}$ & $\begin{array}{c}\text { NR } \\
- \\
-\end{array}$ & $\begin{array}{c}\text { NR } \\
- \\
-\end{array}$ & $\begin{array}{c}\text { NR } \\
+++ \\
++\end{array}$ \\
\hline $\begin{array}{l}\text { B2 } 07 d \\
\text { B2 } 14 d \\
\text { B2 } 21 d\end{array}$ & $\begin{array}{c}++ \\
- \\
- \\
\end{array}$ & $\begin{array}{l}- \\
- \\
-\end{array}$ & $\begin{array}{c}+ \\
+++ \\
- \\
\end{array}$ & $\begin{array}{c}- \\
- \\
+++\end{array}$ & $\begin{array}{l}- \\
- \\
-\end{array}$ & $\begin{array}{l}- \\
+ \\
+\end{array}$ & $\begin{array}{l}- \\
- \\
-\end{array}$ & $\begin{array}{l}+ \\
- \\
-\end{array}$ & $\begin{array}{l}- \\
- \\
-\end{array}$ & $\begin{array}{c}+ \\
+ \\
+++ \\
+++\end{array}$ \\
\hline $\begin{array}{l}\text { B3 } 07 \mathrm{~d} \\
\text { B3 } 14 \mathrm{~d} \\
\text { B3 } 21 \mathrm{~d}\end{array}$ & $\begin{array}{l}+ \\
- \\
+\end{array}$ & $\begin{array}{l}+ \\
- \\
+\end{array}$ & $\begin{array}{c}+ \\
- \\
+++\end{array}$ & $\begin{array}{c}- \\
+++ \\
+\end{array}$ & $\begin{array}{l}- \\
- \\
-\end{array}$ & $\begin{array}{l}- \\
- \\
-\end{array}$ & $\begin{array}{l}- \\
- \\
-\end{array}$ & $\begin{array}{l}- \\
- \\
-\end{array}$ & $\begin{array}{l}- \\
- \\
-\end{array}$ & $\begin{array}{c}++ \\
+++ \\
++\end{array}$ \\
\hline $\begin{array}{l}\text { B4 } 07 d \\
\text { B4 14d } \\
\text { B4 21d } \\
\end{array}$ & $\begin{array}{c}\text { NR } \\
\text { NR } \\
-\end{array}$ & $\begin{array}{c}\text { NR } \\
\text { NR } \\
- \\
\end{array}$ & $\begin{array}{c}\text { NR } \\
\text { NR } \\
- \\
\end{array}$ & $\begin{array}{l}\mathrm{NR} \\
\mathrm{NR} \\
+++\end{array}$ & $\begin{array}{c}\text { NR } \\
\text { NR } \\
- \\
\end{array}$ & $\begin{array}{c}\text { NR } \\
\text { NR } \\
- \\
\end{array}$ & $\begin{array}{c}\text { NR } \\
\text { NR } \\
- \\
\end{array}$ & $\begin{array}{c}\text { NR } \\
\text { NR } \\
- \\
\end{array}$ & $\begin{array}{c}\text { NR } \\
\text { NR } \\
- \\
\end{array}$ & $\begin{array}{l}\mathrm{NR} \\
\mathrm{NR} \\
+++\end{array}$ \\
\hline $\begin{array}{l}\text { B5 } 07 d \\
\text { B5 14d } \\
\text { B5 21 d }\end{array}$ & $\begin{array}{c}\text { NR } \\
- \\
-\end{array}$ & $\begin{array}{c}\text { NR } \\
- \\
- \\
\end{array}$ & $\begin{array}{c}\text { NR } \\
- \\
-\end{array}$ & $\begin{array}{c}\text { NR } \\
+ \\
++ \\
\end{array}$ & $\begin{array}{c}\text { NR } \\
- \\
- \\
\end{array}$ & $\begin{array}{c}\text { NR } \\
- \\
- \\
\end{array}$ & $\begin{array}{c}\text { NR } \\
- \\
- \\
\end{array}$ & $\begin{array}{c}\text { NR } \\
- \\
- \\
\end{array}$ & $\begin{array}{c}\text { NR } \\
- \\
-\end{array}$ & $\begin{array}{l}\text { NR } \\
++ \\
++\end{array}$ \\
\hline $\begin{array}{l}\text { C1 } 07 d \\
\text { C1 } 14 d d \\
\text { C1 } 121 d \\
\end{array}$ & $\begin{array}{c}+++ \\
+ \\
- \\
\end{array}$ & $\begin{array}{c}+++ \\
+ \\
- \\
\end{array}$ & $\begin{array}{c}++ \\
++ \\
-\end{array}$ & $\begin{array}{c}- \\
- \\
++\end{array}$ & $\begin{array}{l}- \\
- \\
-\end{array}$ & $\begin{array}{l}- \\
- \\
-\end{array}$ & $\begin{array}{l}- \\
- \\
- \\
\end{array}$ & $\begin{array}{l}- \\
- \\
-\end{array}$ & $\begin{array}{l}- \\
- \\
-\end{array}$ & $\begin{array}{c}- \\
++ \\
++\end{array}$ \\
\hline $\begin{array}{l}\text { C2 } 07 \mathrm{~d} \\
\text { C2 } 14 \mathrm{~d} \\
\text { C2 } 21 \mathrm{~d}\end{array}$ & $\begin{array}{c}\text { NR } \\
+ \\
\text { NR } \\
\end{array}$ & $\begin{array}{l}\mathrm{NR} \\
+++ \\
\mathrm{NR} \\
\end{array}$ & $\begin{array}{c}\text { NR } \\
- \\
\text { NR } \\
\end{array}$ & $\begin{array}{l}\text { NR } \\
++ \\
\text { NR }\end{array}$ & $\begin{array}{c}\text { NR } \\
- \\
\text { NR } \\
\end{array}$ & $\begin{array}{l}\mathrm{NR} \\
++ \\
\mathrm{NR}\end{array}$ & $\begin{array}{c}\text { NR } \\
- \\
\text { NR } \\
\end{array}$ & $\begin{array}{c}\text { NR } \\
- \\
\text { NR } \\
\end{array}$ & $\begin{array}{c}\text { NR } \\
- \\
\text { NR } \\
\end{array}$ & $\begin{array}{l}\text { NR } \\
++ \\
\text { NR } \\
\end{array}$ \\
\hline $\begin{array}{l}\text { C3 } 07 \mathrm{~d} \\
\text { C3 } 14 \mathrm{~d} \\
\text { C3 } 21 \mathrm{~d} \\
\end{array}$ & $\begin{array}{l}+ \\
- \\
-\end{array}$ & $\begin{array}{c}++ \\
++ \\
-\end{array}$ & $\begin{array}{c}- \\
++ \\
+ \\
\end{array}$ & $\begin{array}{c} \\
- \\
++\end{array}$ & $\begin{array}{l}- \\
+ \\
-\end{array}$ & $\begin{array}{c}+++ \\
- \\
- \\
\end{array}$ & $\begin{array}{l}+ \\
- \\
-\end{array}$ & $\begin{array}{l}- \\
- \\
-\end{array}$ & $\begin{array}{l}- \\
- \\
-\end{array}$ & $\begin{array}{c}- \\
+ \\
++ \\
+\end{array}$ \\
\hline $\begin{array}{l}\text { C4 } 07 \mathrm{~d} \\
\text { C4 14d } \\
\text { C4 } 21 \mathrm{~d} \\
\end{array}$ & $\begin{array}{l}- \\
- \\
-\end{array}$ & $\begin{array}{l}- \\
- \\
-\end{array}$ & $\begin{array}{l}- \\
- \\
+\end{array}$ & $\begin{array}{c}- \\
- \\
++\end{array}$ & $\begin{array}{c}- \\
+++ \\
+++\end{array}$ & $\begin{array}{l}- \\
+ \\
-\end{array}$ & $\begin{array}{c}- \\
++ \\
- \\
\end{array}$ & $\begin{array}{l}- \\
- \\
-\end{array}$ & $\begin{array}{l}- \\
- \\
-\end{array}$ & $\begin{array}{c}- \\
- \\
++\end{array}$ \\
\hline $\begin{array}{l}\text { C5 } 07 \mathrm{~d} \\
\text { C5 } 14 \mathrm{~d} \\
\text { C5 } 21 \mathrm{~d} \\
\end{array}$ & $\begin{array}{c}- \\
\mathrm{NR} \\
-\end{array}$ & $\begin{array}{c}- \\
\mathrm{NR} \\
-\end{array}$ & $\begin{array}{c}- \\
\mathrm{NR} \\
-\end{array}$ & $\begin{array}{c}- \\
\mathrm{NR} \\
-\end{array}$ & $\begin{array}{c}- \\
\mathrm{NR} \\
-\end{array}$ & $\begin{array}{c}- \\
\mathrm{NR} \\
-\end{array}$ & $\begin{array}{c}- \\
\mathrm{NR} \\
+\end{array}$ & $\begin{array}{c}- \\
\mathrm{NR} \\
-\end{array}$ & $\begin{array}{c}- \\
\mathrm{NR} \\
-\end{array}$ & $\begin{array}{c}- \\
\mathrm{NR} \\
-\end{array}$ \\
\hline $\begin{array}{l}\text { D1 } 07 \mathrm{~d} \\
\text { D1 } 14 \mathrm{~d} \\
\text { D1 } 21 \mathrm{~d}\end{array}$ & $\begin{array}{l}+ \\
- \\
-\end{array}$ & $\begin{array}{c}++ \\
- \\
- \\
\end{array}$ & $\begin{array}{c}++ \\
+ \\
- \\
\end{array}$ & $\begin{array}{c}+ \\
- \\
++\end{array}$ & $\begin{array}{l}- \\
- \\
-\end{array}$ & $\begin{array}{c}++ \\
- \\
- \\
\end{array}$ & $\begin{array}{l}- \\
- \\
-\end{array}$ & $\begin{array}{l}- \\
- \\
-\end{array}$ & $\begin{array}{l}- \\
- \\
-\end{array}$ & $\begin{array}{c}++ \\
++ \\
+ \\
\end{array}$ \\
\hline $\begin{array}{l}\text { D2 } 07 \mathrm{~d} \\
\text { D2 } 14 \mathrm{~d} \\
\text { D2 } 21 \mathrm{~d}\end{array}$ & $\begin{array}{l}- \\
- \\
-\end{array}$ & $\begin{array}{l}- \\
- \\
-\end{array}$ & $\begin{array}{c}+ \\
++ \\
-\end{array}$ & $\begin{array}{c}- \\
- \\
+++\end{array}$ & $\begin{array}{l}- \\
- \\
-\end{array}$ & $\begin{array}{l}- \\
+ \\
-\end{array}$ & $\begin{array}{l}+ \\
+ \\
-\end{array}$ & $\begin{array}{l}- \\
- \\
-\end{array}$ & $\begin{array}{l}- \\
- \\
-\end{array}$ & $\begin{array}{l}+ \\
++ \\
++\end{array}$ \\
\hline $\begin{array}{l}\text { D3 } 07 \mathrm{~d} \\
\text { D3 } 14 \mathrm{~d} \\
\text { D3 21 d }\end{array}$ & $\begin{array}{l}- \\
- \\
-\end{array}$ & $\begin{array}{l}- \\
- \\
-\end{array}$ & $\begin{array}{l}+ \\
+ \\
-\end{array}$ & $\begin{array}{c}- \\
- \\
+++\end{array}$ & $\begin{array}{c}- \\
- \\
++\end{array}$ & $\begin{array}{l}- \\
- \\
-\end{array}$ & $\begin{array}{l}- \\
- \\
-\end{array}$ & $\begin{array}{l}- \\
- \\
-\end{array}$ & $\begin{array}{l}- \\
- \\
-\end{array}$ & $\begin{array}{l}+ \\
- \\
+\end{array}$ \\
\hline $\begin{array}{l}\text { D4 07 d } \\
\text { D4 14d } \\
\text { D4 21 d }\end{array}$ & $\begin{array}{c}++ \\
- \\
-\end{array}$ & $\begin{array}{c}+++ \\
- \\
- \\
\end{array}$ & $\begin{array}{c}++ \\
++ \\
-\end{array}$ & $\begin{array}{c}- \\
+ \\
++\end{array}$ & $\begin{array}{l}- \\
+ \\
+\end{array}$ & $\begin{array}{c}- \\
+++ \\
+\end{array}$ & $\begin{array}{l}- \\
+ \\
-\end{array}$ & $\begin{array}{l}- \\
- \\
-\end{array}$ & $\begin{array}{l}- \\
- \\
-\end{array}$ & $\begin{array}{c}++ \\
+++ \\
+++\end{array}$ \\
\hline $\begin{array}{l}\text { D5 } 07 \mathrm{~d} \\
\text { D5 } 14 \mathrm{~d} \\
\text { D5 } 21 \mathrm{~d}\end{array}$ & $\begin{array}{c}\text { NR } \\
\text { NR } \\
-\end{array}$ & $\begin{array}{c}\text { NR } \\
\text { NR } \\
-\end{array}$ & $\begin{array}{l}\text { NR } \\
\mathrm{NR} \\
++ \\
\end{array}$ & $\begin{array}{c}\text { NR } \\
\text { NR } \\
- \\
\end{array}$ & $\begin{array}{c}\text { NR } \\
\text { NR } \\
+ \\
\end{array}$ & $\begin{array}{c}\text { NR } \\
\text { NR } \\
- \\
\end{array}$ & $\begin{array}{c}\text { NR } \\
\text { NR } \\
-\end{array}$ & $\begin{array}{c}\text { NR } \\
\text { NR } \\
- \\
\end{array}$ & $\begin{array}{c}\text { NR } \\
\text { NR } \\
- \\
\end{array}$ & $\begin{array}{c}\mathrm{NR} \\
\mathrm{NR} \\
+++\end{array}$ \\
\hline
\end{tabular}

Quadro 1 - Agrupamento dos resultados obtidos na avaliação histopatológica. A, B, C e D = grupos; 1, 2, 3, 4 e 5= coelhos; $07 \mathrm{~d}=7$ dias; $14 \mathrm{~d}=14$ dias; $21 \mathrm{~d}=21$ dias; - = negativo; + = leve intensidade; $++=$ moderada intensidade; +++ $=$ acentuada intensidade; TFID $=$ Tecido fibrovascular imaturo dérmico; TFMD $=$ Tecido fibrovascular maduro dérmico; DPPH = Dermatite perivascular profunda heterofílica; DPSL = Dermatite perivascular superficial linfoplasmocitária; DIG = Dermatite intersticial granulomatosa; NR = amostra não representativa 
Os grupos tratados com FTCM ou FVE foram eficientes com relação à cicatrização da pele, no entanto, os mecanismos pelos quais as CTMs presentes nestas frações poderiam contribuir para o reparo ou a regeneração do tecido lesado não são ainda totalmente esclarecidos, conforme relataram Templin et al. ${ }^{25}$. A estimulação mitogênica e quimiotática dos queratinócitos pelo TGF- $\alpha$ e EGF promove o início da fase de proliferação epitelial e a formação do tecido de granulação ${ }^{26}$. Da mesma maneira, CTM como as presentes nas frações, também poderiam contribuir para a regeneração da epiderme, se diferenciando em queratinócitos ${ }^{27}$. $\mathrm{Na}$ fase de remodelagem, iniciada 17 a 21 dias após a lesão ${ }^{5}$, ocorreu a cicatrização completa das feridas. Segundo relataram Karukonda et al. ${ }^{28}$, células-tronco adultas juntas com outros tipos celulares poderiam contribuir com a produção de fibroblastos na pele, elevando a produção de citocinas e desta maneira permitindo que o reparo cutâneo apresente uma cicatriz mais estética, em menor tempo.

A cicatrização completa das feridas foi considerada quando ocorria o encontro das margens, resultando na inibição da contração pelo contato, conforme determinado por Hosgood ${ }^{29}$. O grupo tratado com a FVE foi o único a apresentar diferença estatística significativa na planimetria ( $\mathrm{p}<0,0001)$, logo na primeira semana do período de avaliação, mesmo com uma quantidade total de células mononucleares aplicadas e uma viabilidade mais baixa quando comparada com a FTCM. Além disso, o grupo tratado com a FVE apresentou cicatrização completa de suas feridas aos 18 dias de pós-operatório, em média, enquanto que a

\section{Referências}

1.GARTNER, L.; HIATT, J. Tegumento. In: GARTNER, L.; HIATT, J. Tratado de histologia em cores. 2. ed. Rio de Janeiro: Guanabara Koogan, 2003. cap. 14, p. 265-279.

2.JUNQUEIRA, L. C.; CARNEIRO, J. Pele e anexos. In: JUNQUEIRA, L. C.; CARNEIRO, J. Histologia básica. 10. ed. Rio de Janeiro: Guanabara Koogan, 2004. cap. 6, p. 360370 .

3. REHEN, S.; PAULSEN, B. Células-tronco: o que são? Para que servem? Rio de Janeiro: Vieira e Lent, 2007. 90 p.

4.STEVENS, A.; LOWE, J. Pele e glândula mamária. In: cicatrização das feridas do grupo que recebeu FTCM ocorreu, em média, aos 19 dias. Isto pode ser explicado, segundo Strem et al..$^{30}$ pelo fato do tecido adiposo conter de 100 a 1000 vezes mais células pluripotentes em um centímetro cúbico do que a medula.

\section{Conclusões}

Nas condições em que foi realizado o experimento e com base nos resultados obtidos é possível concluir que: 1) a membrana celulósica utilizada como scaffold sobre a ferida acelerou o processo de cicatrização, na avaliação da planimetria a partir dos 14 dias de pósoperatório, quando comparado com o grupo controle; 2) tanto a aplicação local da FTCM autógena da MO quanto da FVE autógena do TA também aceleraram o tempo de reparação cutânea e, embora não tenha havido diferença estatística entre os três grupos tratados ao término do período de avaliação, a aplicação da FVE foi a única a apresentar diferença estatística na planimetria, já aos sete dias de pós-operatório, quando comparado com o controle e a cicatrização completa das feridas deste grupo, ocorreu mais precocemente, aos 18 dias de pós-operatório, em média; 3 ) sugerem-se novos estudos, especialmente com cultivo celular, sobre o reparo da pele.

\section{Agradecimentos}

Os autores agradecem à CAPES pelo financiamento da bolsa de mestrado que possibilitou a realização desta pesquisa.

STEVENS, A.; LOWE, J. Histologia. 1. ed. São Paulo: Manole, 1995. cap. 19, p. 348-363.

5.HEDLUND, C. S. Cirurgia do sistema tegumentar. In: FOSSUM, T. W. (Org.). Cirurgia de pequenos animais. 2. ed. São Paulo: Roca, 2005. p. 135-230.

6.ROSA, M. G. S.; PIPPI, N. L.; CASTRO, M. A. S. Transplante de pele pela técnica de semeadura em cães. Ciência Rural, Santa Maria, v. 13, n. 2-3, p. 203-209, 1983.

7.FOWLER, D. Distal limb and paw injuries. Veterinary Clinics Small Animal Practice, v. 36, p. 819-845, 2006. 
8. HEDLUND, C. S. Large trunk wounds. Veterinary Clinics Small Animal Practice, v. 36, p. 847-872, 2006.

9. POPE, E. R. Head and facial wounds in dogs and cats. Veterinary Clinics Small Animal Practice, Maryland, v. 36, p. 793-817, 2006.

10.BOJRAB, M. J. Cicatrização da pele. In: BOJRAB, M. J. Mecanismos da moléstia na cirurgia dos pequenos animais. 2. ed. São Paulo: Manole, 1996. p. 178-183.

11.FORTIER, L. A. Stem cells: classifications, controversies, and clinical applications. Veterinary Surgery, Davis, v. 34, p. 415$423,2005$.

12.MEIRELLES, L. S.; CHAGASTELLES, P. C.; NARDI, N. B. Mesenchymal stem cells reside in virtually all post-natal organs and tissues. Journal of Cell Science, v. 119, p. 22042213,2006

13.MOSELEY, T. A.; ZHU, M.; HEDRICK, M. H. Adipose-derived stem and progenitor cells as fillers in plastic and reconstructive surgery. Plastic and Reconstructive Surgery, v. 118, p. 121128,2006 . Suppl.

14.GIMBLE, J. M.; KATZ, A. J.; BUNNELL, B. A. Adipose-derived stem cells for regenerative medicine. Journal of the American Heart Association, v. 100, p. 1249-1260, 2007.

15.ALMEIDA, K. A.; CAMPA, A; CARDOSO ALONSOVALE, M. I.; BESSA LIMA, F.; DIB DAUD, E.; NOGUEIRA STOCCHERO, I. Fracción vascular estromal de tejido adiposo: cómo obtener células adre y su rendimiento de acuerdo a la topografía de las áreas donantes: estudio preliminar. Cirurgia Plástica Iberolatinoamericana, v. 34, n. 1, p. 71-79 2008.

16.WILLIAMS, K. J.; PICOU, A. A.; KISH, S. L.; GIRALDO, A. M.; GODKE, R. A.; BONDIOLLI, K. R. Isolation and characterization of porcine adipose tissue-derived adult stem cells. Cells Tissues Organs, v. 188, n. 3, p. 251-258, 2008.

17.PARK, B. S.; JANG, K. A.; SUNE, J. H.; PARK, J. S.; KWON, Y. H.; KIM, J.; KIM, W. S. Adipose-derived stem cells and their secretory factors as a promissing therapy for skin aging. American Society for Dermatologic Surgery, v. 34, n. 10, p. 1323-1326, 2008.

18. OLSSON, D. C. Transplante de células-tronco com a fração total de células mononucleares autógenas da medula óssea na lesão aguda iatrogênica de tendão calcâneo comum de cães. 2009. 106 f. Tese (Doutorado em Medicina Veterinária) - Faculdade de Veterinária, Universidade Federal de Santa Maria, Santa Maria, 2009.

19.WELSH, K.; MALE, D. Transplante e rejeição. In: ROITT, I.; BROSTOFF, J.; MALE, D. Imunologia. 2. ed. São Paulo: Manole, 1992. p. 24.1-10.
20.BURKE, J. F.; YANNAS, I. V.; QUIMBY JR., W. C.; BONDOC, C. C.; JUNG, W. K. Successful use of a physiologically acceptable artificial skin in the treatment of extensive burn injury. Annals of Surgery, v. 194, n. 4, p. 413-428, 1981.

21.HOUSMAN, T. S.; LAWRENCE, N.; MELLEN, B. G.; GEORGE, M. N.; FILIPPO, J. S.; CERVENY, K. A.; DEMARCO, M.; FELDMAN, S. R.; FLEISCHER, A. B. The safety of liposuction: results of a national survey. Dermatologic Surgery, v. 28, n. 11, p. 971-978, 2002.

22.SALBEGO, F. Z. Enxerto ou implante homólogo na correção de defeito ósseo segmentar em cães associado à inoculação da fração de células mononucleares da medula óssea. 2010. 211 f. Tese (Doutorado em Medicina Veterinária) - Faculdade de Veterinária, Universidade Federal de Santa Maria, Santa Maria, 2010.

23. GENGOZIAN, N. Identification and isolation of hematopoietic progenitors. In: FELDMAN, B. F.; ZINKL, J. G.; JAIN, N. C. (Ed.). Schalm's veterinary hematology. 5. ed. Philadelphia: Williams \& Wilkins, 2000. cap. 16, p. 91-96.

24.CLARK, R. A. The molecular and cellular biology wound repair. 2. ed. New York: Plenum Press, 1996.

25.TEMPLIN, C.; GROTE, K.; SCHLEDZEWSKI, K.; GHADRI, J. R.; SCHNABEL, S.; NAPP, L. C.; SCHIEFFER, B.; KURZEN, H.; GOERDT, S; LANDMESSER, U.; KOENEN, W.; FAULHABER, J. Ex vivo expanded haematopoietic progenitor cells improve dermal wound healing by parácrino mechanisms. Experimental Dermatology, v. 18, p. 445-453, 2009.

26.FRADE, M. A. Úlcera de perna: caracterização clínica e perfil imunohistopatológico do reparo tecidual na presença da biomembrana de látex natural da seringueira Hevea brasiliensis. Ribeirão Preto: Faculdade de Medicina de Ribeirão Preto - USP, 2003.

27.SASAKI, M.; ABE, R.; FUJITA, Y.; ANDO, S.; INOKUMA, D.; SHIMIZU, H. Mesenchymal stem cells are recruited into wounded skin and contribute to wound repair by transdifferentiation into multiple skin cell type. The Journal of Immunology, v. 180, n. 5, p. 2581-2587, 2008.

28.KARUKONDA, S. R.; FLYNN, T. C.; BOH, E. E.; MCBURNEY, E. I.; RUSSO, G. G.; MILLIKAN, L. E. The effects of drugs on wound healing - part II. Specific classes of drugs and their effect on healing wounds. International Journal of Dermatology, v. 39, n. 5, p. 321-333, 2000.

29. HOSGOOD, G. Reparo de feridas e resposta tecidual específica à lesão. In: SLATTER, D. Manual de cirurgia de pequenos animais. 3. ed. São Paulo: Manole, 2007. p. 66-86.

30.STREM, B. M.; HICOK, K. C.; ZHU, M.; WULUR, I.; ALFONSO, Z.; SCHREIBER, R. E.; FRASER, J. K.; HEDRICK, M. H. Multipotential differentiation of adipose tissue-derived stem cells. Keio Journal Medicine, v. 54, p. 132, 2005. 